\title{
HETEROGENEOUS REACTIONS WITH NaCl IN THE EL CHICHON VOLCANIC AEROSOLS
}

\author{
Diane V. Michelangeli \\ Space Science Division, NASA Ames Research Center \\ Mark Allen
}

Earth and Space Sciences Division, Jet Propulsion Laboratory, California Institute of Technology

Yuk. L. Yung

Division of Geological and Planetary Sciences; California Institute of Technology

\begin{abstract}
Previous investigations of the effects of the 1982 eruption of the El Chichon volcano could not explain all the observations of changes in $\mathrm{O}_{3}, \mathrm{HCl}, \mathrm{NO}$ and $\mathrm{NO}_{2}$ simultaneously without proposing unproven chemical reactions. Since reactions between solid $\mathrm{NaCl}$ and gaseous $\mathrm{ClNO}_{3}$ and $\mathrm{N}_{2} \mathrm{O}_{5}$ rapidly produce photochemically active chlorine species and solid $\mathrm{NaNO}_{3}$ in laboratory experiments, we suggest that these reactions could have occurred with the $\mathrm{NaCl}$ observed to be present in the El Chichon sulfuric acid aerosols. As a consequence, we predict that $\mathrm{HCl}$ should increase substantially; while $\mathrm{NO}_{x}$ should decrease, in agreement with the measurements after the eruption. Ozone should only be slightly affected by these reactions. Reactions between solid $\mathrm{NaCl}$ and the acids $\mathrm{H}_{2} \mathrm{SO}_{4}$ and $\mathrm{HNO}_{3}$ might prove to be important, but we lack suffcient evidence regarding their efficiency and the presence of $\mathrm{HNO}_{3}$ in the aerosols to be more conclusive.
\end{abstract}

\section{Introduction}

The eruption of the El Chichon volcano in Mexico in March-April 1982 [see for example Pollack et al., 1983] provided stratospheric chemists with an excellent opportunity to test their models by trying to simulate the effects of this known perturbation to the atmosphere. $\mathrm{SO}_{2}$ was directly injected into the stratosphere [Krueger, 1983] and rapidly converted to sulfuric acid aerosols [Hoffmann and Rosen, 1984]. The aerosol cloud, located between 16 and $30 \mathrm{~km}$ [DeLuisi et al., 1983] was still observable one year after the eruption [Hoffmann and Rosen, 1983; Thomas et. al., 1983; Adriani et al., 1983; Spinhirne and King, 1985; Jäger and Carnuth, 1987).

Michelangeli et al. [1989] investigated the chemical changes in the stratosphere during the first three months after the formation of the aerosol cloud. They used a one dimensional radiative transfer multiple scattering code [Michelangeli et al., 1990] to evaluate the changes in the total actinic flux after the eruption. The particles were efficient forward scalterers which lead to a total radiation increase of up to $8 \%$ between 3000 and $8000 \AA$ in the aerosol layer (for more details see Michelangeli et al. [1989] and Michelangeli et al. [1990]). Michelangeli et al. [1989] included both this radiation change and $3^{\circ} \mathrm{C}$ temperature

Copyright 1991 by the American Geophysical Union.

Paper number 91GL00547

$0094-8534 / 91 / 91 G L-00547 \$ 03.00$ changes (observed by Labitzke et al. [1983] and modelled by Pollack and Ackerman [1983]) in a one dimensional chemical kinetics model of the stratosphere. While they obtained a decrease in ozone which agreed with the observations of Heath and Schlesinger [1984] and Chandra [1987], they could not explain the measured $40 \%$ increase in $\mathrm{HCl}$ [Mankin and Coffey, 1984; B. W. Gandrud and A. L. Lazrus, private communication, 1983], as well as the large $\mathrm{NO}$ and $\mathrm{NO}_{2}$ decreases (McFarland et al., 1986; Roscoe et al., 1986], even after including direct injections of $\mathrm{HCl}, \mathrm{Cl}_{2}$ and $\mathrm{H}_{2} \mathrm{O}$ from the volcano into the stratosphere.

Therefore, Michelangeli et al. [1989] explored the role of heterogeneous reactions on sulfuric acid aerosols in reproducing the available measurements. This was suggested by the importance of reactions between the ice particles of the polar stratospheric clouds and gas phase molecules $\left(\mathrm{N}_{2} \mathrm{O}_{5}, \mathrm{ClNO}_{3}, \mathrm{HCl}, \mathrm{H}_{2} \mathrm{O}\right)$ for explaining the Antarctic ozone hole [Solomon et al., 1986; McElroy, 1986; Molina. et al., 1987; Tolbert et al., 1988]. Using the laboratory results of Rossi et al. [1987], Tolbert et al. [1988] and Worsnop et al. [1988] for the efficiency (or sticking coefficient, $\gamma$ ) of reactions on $\mathrm{H}_{2} \mathrm{SO}_{4} / \mathrm{H}_{2} \mathrm{O}$ drops, Michelangeli et al. [1989] simulated the effects of various heterogeneous reactions involving $\mathrm{ClO}_{x}$ and $\mathrm{NO}_{x}$ species in their model. They concluded that the speculative heterogeneous reaction $\mathrm{ClNO}_{3} \rightarrow \mathrm{HCl}$ (with product $\mathrm{NO}_{x}$ retained in the aerosol) was the most effective process. Other reactions considered led to changes in the opposite sense to what was observed and/or in the correct sense, but too amall in magnitude. Unfortunately, there are currently no laboratory results proving the direct heterogeneous conversion of $\mathrm{ClNO}_{3}$ to HCl. Hoffmann and Solomon [1989] did a similar study of heterogeneous reactions with a twodimensional model, but they did not include simultaneously the radiation and temperature changes:

Finlayson-Pitts [1983] and Finlayson-Pitts et al. [1989] presented results that indicated that gaseous $(\mathrm{g}) \mathrm{NO}_{2}$, $\mathrm{N}_{2} \mathrm{O}_{5}$ and $\mathrm{ClNO}_{3}$ react with solid (s) $\mathrm{NaCl}$ in the following manner:

$$
\begin{aligned}
2 \mathrm{NO}_{2}(g)+\mathrm{NaCl}(s) & \rightarrow \mathrm{NOCl}(g)+\mathrm{NaNO}_{9}(s) \\
\mathrm{ClNO}_{3}(g)+\mathrm{NaCl}(s) & \rightarrow \mathrm{Cl}_{2}(g)+\mathrm{NaNO}_{3}(s) \\
\mathrm{N}_{2} \mathrm{O}_{5}(g)+\mathrm{NaCl}(s) & \rightarrow \mathrm{ClNO}_{2}(g)+\mathrm{NaNO}_{3}(s)
\end{aligned}
$$

An early measurement (as quoted in Finlayson-Pitts, 1983 ) indicated that $\gamma \approx 10^{-0}-10^{-7}$ for reaction ( 1 ). Re- 
cent experiments [F.E. Livingston and B. Finlayson-Pitts, 1991] suggested that $\gamma$ for reaction (1) is smaller $\left(10^{-8}\right)$ and that $\gamma>5 \times 10^{-3}$ for reaction (3). No sticking coefficient information is available for reaction (2).

The reactions proceed at $298 \mathrm{~K}$, but no data are available at the colder stratospheric temperatures $(\sim 225$ $\mathrm{K}$ at $28 \mathrm{~km}$, the peak of the aerosol layer). FinlaysonPitts et al. [1989], on the basis of Molina et al. [1987], suggest that the reactions might be more efficient at low temperatures because of the increased residence time of the species on the particles. The reactions on the surface are ionic in nature and should not have an activation barrier. The lack of quantitative experimental information at low temperatures inhibits detailed numerical simulations of the effects of reactions (1)-(3), but a qualitative assessment of their possible impact is feasible.

\section{Results and Discussion}

The first question we need to address is whether or not $\mathrm{NaCl}$ is present in volcanic aerosols. The only direct evidence for the presence of halite in the El Chichon aerosol cloud is from the in situ measurements of Woods et at. [1985] using a quartz crystal microbalance cascade impactor on a U-2 aircraft between 18 and $21 \mathrm{~km}$. On May $5^{\text {th }}, 1982$, they estimated that $7 \%$ of the total aerosol mass (or $0.5 \mu \mathrm{g} \mathrm{m}^{-3}$ ) was $\mathrm{NaCl}$. No halite was measurable during flights in July, November and December. Woods et al. [1985] claim that the detection of halite and its apparent disappearance by July could explain the large depolarization ratios measured in early May 1982 by Hayashida et al. [1984] and a return to normal values in late May.

Woods et al. [1985] explain the disappearance of $\mathrm{NaCl}$ by invoking the reaction $\mathrm{H}_{2} \mathrm{SO}_{4}+2 \mathrm{NaCl}(\mathrm{s}) \rightarrow \mathrm{Na}_{2} \mathrm{SO}_{4}$ (s) $+2 \mathrm{HCl}$. To validate their theory they searched for $\mathrm{Na}_{2} \mathrm{SO}_{4}(\mathrm{~s})$ in their samples, and only found it present in the May 5th sample when it was reexamined in November. This suggests that the reaction occurred within the sample after it was collected, but does not prove that it was important in the atmosphere. Woods et al. [1985] state that the $\mathrm{NaCl}$ started to convert to $\mathrm{Na}_{2} \mathrm{SO}_{4}$ only after one month. Pinto et al. [1989] argue that this reaction might be limited by the sedimentation of $\mathrm{NaCl}$ within a month, and the lack of sufficient regeneration of $\mathrm{H}_{2} \mathrm{SO}_{4}$ frum $\mathrm{SO}_{2}$.

While there is uncertainty regarding the presence of $\mathrm{Na}_{2} \mathrm{SO}_{4}$ (s), as well as the lifetime of $\mathrm{NaCl}(\mathrm{s})$, it seems clear that halite was still present at significantly high concentrations one month after the eruption. Since $\mathrm{H}_{2} \mathrm{SO}_{4}$ is not thought to react during that time according to Woods et al. [1985], it leaves time for reactions (1)-(3) to occur, and then helps explain the disappearance of halite by July. From the Woods et al. [1985] measurements we deduce that the concentration of $[\mathrm{NaCl}]=5.15 \times 10^{\circ} . \mathrm{cm}^{-3}$ near $20 \mathrm{~km}$. To obtain the concentration at $28 \mathrm{~km}$ (peak of aerosol cloud) we use the lidar measurements of DeLuisi et al. [1983] for the aerosol scattering: $40 \%$ of the aerosols were located at $28 \mathrm{~km}$, while $7 \%$ were present at $20 \mathrm{~km}$. A simple scaling leads to an $\mathrm{NaCl}$ amount at $28 \mathrm{~km}$ of $2.94 \times 10^{10} \mathrm{~cm}^{-3}$. While this figure is probably a large overestimate, it gives the order of magnitude we are considering. We can then compare this to the standard gas abundances in the non-perturbed photochemical model: $\left[\mathrm{NO}_{2}\right]=2.6 \times 10^{9} \mathrm{~cm}^{-3},\left[\mathrm{ClNO}_{3}\right]=4.4 \times 10^{8} \mathrm{~cm}^{-3}$, and $\left[\mathrm{N}_{2} \mathrm{O}_{5}\right]=5.7 \times 10^{8} \mathrm{~cm}^{-3}$ at $28 \mathrm{~km}$. From these numbers it is clear that the amount of $\mathrm{NaCl}$ will not be the limiting factor in the rates of reactions (1)-(3).

Livingston and Finlayson-Pitts (1991), while studying reaction (3) concluded that $\mathrm{HNO}_{3}(\mathrm{~g})+\mathrm{NaCl}(\mathrm{s}) \rightarrow$ $\mathrm{HCl}$ (g) $+\mathrm{NaNO}_{3}$ (s) might also be occurring in their system. However, no quantitative kinetic rates were re ported. Conceivably this could also take place in the stratosphere with very high efficiency. While this reaction could be very effective at reducing $\mathrm{NO}_{x}$ and increasing $\mathrm{HCl}$, it requires that $\mathrm{HNO}_{3}$ be in, or in contact with, the aerosols, which are already very acidic, consisting roughly of $75 \% \mathrm{H}_{2} \mathrm{SO}_{4}$. This might prove to be the main limitation to the efficiency of this reaction. So far there is no evidence suggesting the presence of $\mathrm{HNO}_{3}$ in volcanic aerosols. The reaction would also lead to a significant reduction in $\mathrm{HNO}_{3}$ which was not observed after the eruption [Mankin and Coffey, 1986; Amold et al., 1990].

All three proposed reactions ((1)-(3)) take newly injected $\mathrm{Cl}$ from $\mathrm{NaCl}$ and convert it to photolytically unstable chlorine-containing compounds $\left(\mathrm{Cl}_{2}, \mathrm{NOCl}\right.$, $\mathrm{ClNO}_{2}$ ). The $\mathrm{Cl}$ produced is active and can possibly lead to an increase in $\mathrm{HCl}$, the most stable chlorine-containing species. Furthermore, reaction (2) has the added advantage of taking $\mathrm{Cl}$ from the more inert $\mathrm{ClNO}_{3}$ and converting it to reactive $\mathrm{Cl}_{2}$. Therefore, for every $\mathrm{NaCl}$ that reacts with $\mathrm{CINO}_{3}$, we produce $2 \mathrm{Cl}$ atoms. This would lead to a very large source of extra chlorine, and therefore could lead to an $\mathrm{HCl}$ increase.

As far as increasing $\mathrm{HCl}$ is concerned, there are two differences with the cases presented by Michelangeli et al. [1989]. First, reaction (2) differs from the reaction between $\mathrm{CINO}_{3}$ and $\mathrm{HCl}$ by not destroying $\mathrm{HCl}$ directly, and by introducing an extra $\mathrm{Cl}$ source to the stratosphere. Second, in the previous work, the simulations of a direct $\mathrm{Cl}_{2}$ or $\mathrm{HCl}$ injection into the stratosphere failed to produce an overall $\mathrm{HCl}$ increase after three months, because the chemistry was perturbed in a single pulse, and then left to relax back to the steady state. The large gradient in $\mathrm{HCl}$ was quickly smoothed out by diffusion. Pinto et al. [1989] also suggest that $\mathrm{HCl}$ should be washed out rapidfy. In the case we propose now, the heterogeneous reactions would progress at a slower rate, releasing $\mathrm{Cl}$ gradually to the stratosphere. It would then be possible for a new state to be reached after three months. Even though $\mathrm{NaCl}$ was injected in a pulse, observations discussed earlier suggest it was present in the aerosol for at least one month. Contrary to this, both of the reactions between $\mathrm{NaCl}$ and acid $\left(\mathrm{H}_{2} \mathrm{SO}_{4}\right.$ or $\left.\mathrm{HNO}_{3}\right)$, if they occur, produce $\mathrm{HCl}$ directly, and probably very rapidly. This would then result in a situation very similar to that of the direct $\mathrm{HCl}$ injection, and therefore would not be effective at increasing $\mathrm{HCl}$ three months after the eruption.

Reactions (1)-(3) have the added advantage of having an impact on $\mathrm{NO}_{x}$ chemistry as well. All three reactions convert active $\mathrm{NO}_{y}$ species $\left(\mathrm{NO}_{2}, \mathrm{ClNO}_{3}, \mathrm{~N}_{2} \mathrm{O}_{5}\right)$ to $\mathrm{NaNO}_{3}(\mathrm{~s})$ in the aerosols which can fall out of the atmosphere. $\mathrm{NaNO}_{3}$ will not return $\mathrm{NO}_{x}$ to the stratosphere such as would the $\mathrm{NOCl}(\mathrm{g})$ and $\mathrm{ClNO}_{2}(\mathrm{~g})$ produced in (1) and (3). Even in these two reactions $\mathrm{NaNO}_{3}(\mathrm{~B})$ is 
produced and, therefore, they might be effective in at least reducing $\mathrm{NO}_{x}$. In addition, $\mathrm{NO}_{2}$ is now directly involved in heterogeneous reactions. In this case, a reaction between $\mathrm{NaCl}$ and $\mathrm{HNO}_{3}$ would be very effective at reducing $\mathrm{NO}_{\mathrm{z}}$. Unfortunately, this cannot be quantified for lack of data on the reaction.

These results are extremely uncertain owing to the unknown heterogeneous reaction efficiencies at low temperatures. However, we can see whether these processes ((1)(3)) have the potential of being important. They will be in competition with reactions such as

$$
\begin{aligned}
\mathrm{N}_{2} \mathrm{O}_{5}+h \nu & \rightarrow \mathrm{NO}_{2}+\mathrm{NO}_{3} \\
\mathrm{OH}+\mathrm{NO}_{2}+M & \rightarrow \mathrm{HNO}_{3}+M \\
\mathrm{ClNO}_{3}+h \nu & \rightarrow \mathrm{Cl}+\mathrm{NO}_{3} .
\end{aligned}
$$

Some simple calculations show the relative importance of these reactions. First, we assume that when a gas molecule $\left(\mathrm{NO}_{2}, \mathrm{ClNO}_{9}\right.$ or $\left.\mathrm{N}_{2} \mathrm{O}_{5}\right)$ sticks to a particle, it is in contact with $\mathrm{NaCl}$ and can react. We therefore can calculate the loss frequency due to collisions with $\mathrm{NaCl}(\mathrm{s})$ by $J_{\mathrm{NaCl}}=1 / 4 \gamma v A N_{a}$ where $v$ is the mean speed of the impacting molecule $v=\sqrt{8 k T / \pi m}, A$ is the mean surface area $\left(6.4 \times 10^{-8} \mathrm{~cm}^{2}\right.$, assuming that the geometrical and optical cross sections are the same), and $N_{a}$ is the number density of the aerosols $\left(26 \mathrm{~cm}^{-3}\right.$ at 28 $\mathrm{km}$ ). Assuming sticking coefficients for $\mathrm{NO}_{2}$ and $\mathrm{N}_{2} \mathrm{O}_{5}$ are $\gamma=10^{-8}$ and $5 \times 10^{-3}$, respectively, we obtain the corresponding loss frequencies for heterogeneous reaction with $\mathrm{NaCl}, J_{\mathrm{NaC}: 1}=1.4 \times 10^{-10}$ and $4.5 \times 10^{-5} \mathrm{~s}^{-1}$, respectively. The loss frequency due to $\mathrm{CINO}_{3}$ is not known, but is probably close to that for $\mathrm{N}_{2} \mathrm{O}_{5}$. We compare these with the loss frequencies for reactions (4)-(6), which are $J_{4}=3.82 \times 10^{-5} \mathrm{~s}^{-1}, J_{5}=1.32 \times 10^{-5} \mathrm{~s}^{-1}$, and $J_{6}=$ $1.08 \times 10^{-4} \mathrm{~s}^{-1}$. The loss frequencies of reactions (4)-(6) are higher than for the reactions between $\mathrm{NO}_{2}$ and $\mathrm{NaCl}$, but are not so different for $\mathrm{N}_{2} \mathrm{O}_{5}$ and possibly $\mathrm{CINO}_{3}$. The heterogeneous reactions represent a permanent sink for $\mathrm{NO}_{\mathbf{x}}$ and can produce a $\mathrm{Cl}$ increase, followed by an $\mathrm{HCl}$ increase.

If we assume that one $\mathrm{NO}_{2}(\mathrm{~g})$ is lost for each $\mathrm{NaNO}_{3}(\mathrm{~s})$ formed, the $\mathrm{NO}_{2}$ concentration at $28 \mathrm{~km}$ will decrease by $50 \%\left(1.3 \times 10^{8}\right.$ molecules $\mathrm{cm}^{-3}$; McFarland et al., 1986; Roscoe et al., 1986) after 14 hours by reaction (3). At the same altitude, reaction (2) could lead to a $40 \%$ increase in $\mathrm{HCl}\left(1.72 \times 10^{8}\right.$ molecules $\mathrm{cm}^{-3} ; \mathrm{B}$. W. Gandrud and A. L. Lazrus, private communication, 1983) in 3.4 days. If the loss timescale for $\mathrm{HCl}$ due to vertical transport is $\sim 1$ month, the elevated $\mathrm{HCl}$ abundance can be sustained with $\gamma$ for (2) as small as $10^{-5}$. Therefore, the proposed heterogeneous chemistry can be relatively inefficient and still reproduce observations. Reaction (1) is, however, too slow to have any impact. Since these reactions occur rapidly, there should be no problem caused by $\mathrm{NaCl}$ sedimentation, since we know halite is present for a month.

An important uncertainty is the location of the reaction. Once the surface layer of $\mathrm{NaCl}$ has been oxidized to $\mathrm{NaNO}_{3}$, it is not clear whether or not the reaction will continue in the interior and release $\mathrm{HCl}(\mathrm{g})$. Livingston and Finlayson-Pitts (1991) suggest that reaction (3) occurs on the surface of the halite crystals in their experimental system. Further laboratory investigations are required to understand and quantify this process more pre- cisely. Also, the presence of $\mathrm{NaCl}$ in volcanic aerosols has not been extensively reported in the literature, and therefore remains an uncertainty. It is crucial that, in the event of another volcanic eruption more in situ aerosol measurements be taken, and that the abundance of $\mathrm{NaCl}$ be definitively established. In addition, it would be important to look for $\mathrm{NaNO}_{3}$ and $\mathrm{Na}_{2} \mathrm{SO}_{4}$ in the aerosols.

Since the ultimate fate of the $\mathrm{NaNO}_{3}$ is to fall out of the stratosphere, a close examination of the Greenland and Antarctic ice cores would be worthwhile. The acidic layer corresponding to $\mathrm{El}$ Chichon has been detected in Greenland ice cores. It would be interesting to look for the presence of $\mathrm{NaNO}_{3}$ or $\mathrm{Na}_{2} \mathrm{SO}_{4}$ after the eruption. Unfortunately, due to the rapid fall times limiting the amount of $\mathrm{NaNO}_{3}$ (s) and $\mathrm{Na}_{2} \mathrm{SO}_{4}$ (s) that can reach the polar regions, and the large tropospheric contribution of $\mathrm{Na}^{+}, \mathrm{NO}_{3}{ }^{-}$, and $\mathrm{SO}_{4}{ }^{2-}$ this will probably be very difficult, if not impossible.

If the impact of reactions (1)-(3) is similar to that of the speculative chemistry proposed in Michelangeli et al. (1989) which reproduces the $\mathrm{HCl}$ and $\mathrm{NO}_{x}$ measurements, an ozone decrease of a few percent can be expected. This is not considered a disagreement with the observations since there is easily a few percent uncertainty in all the assumed parameters for the model calculation. However, because of the complex nature of the various interactions between the $\mathrm{NO}_{x}$ and $\mathrm{ClO}_{x}$ species and $\mathrm{O}_{3}$ in the stratosphere, the ultimate fate of $\mathrm{O}_{3}$ can only be determined by detailed photochemical modeling.

Heterogeneous reactions with $\mathrm{NaCl}$ seem to have the potential of having a major impact on stratospheric chemistry after the eruption of $\mathrm{El}$ Chichon. A detailed numerical study awaits further laboratory results. The ultimate question is whether or not this mechanism might have been even more significant during earlier larger volcanic eruptions.

Acknowledgements. We thank M.-T. Leu for valuable discussions and B. Finlayson-Pitts for communication of laboratory results prior to publication. We also are grateful to the anonymous reviewers for pointing out the deficiencies of our initial presentation. This work was supported by NAGW-413 to California Institute of Technology. One of us (DVM) acknowledges support of a NASA NRC Fellowship. Contribution number 4898 from the Division of Geological and Planetary Sciences, California Institute of Technology, Pasadena, California 91125.

\section{References}

Adriani, A., F. Congeduti, G. Fiocco, and G. P. Gobbi, One-year lidar observations of the stratospheric aerosol at Frascati, March, 1982-March, 1983, Geophys. Res. Lett., 10, 1005-1008, 1983.

Arnold, F., Th. Bührke, and S. Oiu, Evidence for stratospheric ozone-depleting heterogeneous chemistry on volcanic aerosols from El Chichon, Nature, 348, 49-50, 1990.

Chandra, S., The aerosol effects on ozone measurements following the eruption of El Chichon, EOS: Transactions, American Geophysical Union, 68, 370, 1987.

DeLuisi, J. J., E. G. Dutton, K. L. Coulson, T. E. DeFoor, and B. G. Mendonca, On some radiative features of 
the El Chichon volcanic stratospheric dust cloud and a cloud of unknown origin observed at Mauna Loa, $J$. Geophys. Res., 88, 6769-6772, 1983.

Finlayson-Pitts, B. J., Reaction of $\mathrm{NO}_{2}$ with $\mathrm{NaCl}$ and atmospheric implications of $\mathrm{NOCl}$ formation, Nature, 306, 676-677, 1983.

Finlayson-Pitts, B. J., M. J. Ezell, and J. N. Pitts, Jr., Formation of chemically active chlorine compounds by reactions of atmospheric $\mathrm{NaCl}$ particles with gaseous $\mathrm{N}_{2} \mathrm{O}_{5}$ and $\mathrm{ClONO}_{2}$, Nature, 337, 241-244, 1989.

Hayashida, S., et al., Water Research Institute, Middle Atmospheric Program, note 3, 1984.

Heath, D. F. and B. M. Schlesinger, Global response of stratospheric ozone to natural perturbations on climatological time scales by variations of UV solar flux and the eruption of El Chichon, EOS: Transactions, American Geophysical Union, 65, 836-837, 1984.

Hoffmann, D. J. and J. M. Rosen, Stratospheric sulfuric acid fraction and mass estimate for the 1982 .volcanic eruption of El Chichon, Geophys. Res. Lett., 10, 313-316, 1983.

Hoffmann, D. J. and J. M. Rosen, On the temporal variation of stratospheric aerosol size and mass during the first 18 months following the 1982 eruptions of El Chichon, J. Geophys. Res., 89, 4883-4890, 1984.

Hoffmann, D. J., and S. Solomon, Ozone destruction through heterogeneous chemistry following the eruption of El Chichon, J. Geophys. Res., 94, 5029-5041, 1989.

Jăger, H. and W. Carnuth, The decay of the El Chichon stratospheric perturbation, observed by Lidar at Northern midlatitudes, Geophys. Res. Lett., 14, 696-699, 1987.

Krueger, A. J., Sighting of El Chichon sulfur dioxide clouds with the Nimbus 7 total ozone mapping spectrometer, Science, 220, 1377, 1983.

Labitzke, K., B. Naujokat, and M. P. McCormick, Temperature effects on the stratosphere of the April 4, 1982 eruption of El Chichon, Mexico, Geophys. Res. Lett., 10, 24-26, 1983.

Livingston, F. E., and B. J. Finlayson-Pitts, The reaction of gaseous $\mathrm{N}_{2} \mathrm{O}_{5}$ with solid $\mathrm{NaCl}$ at $298 \mathrm{~K}$ : Estimated lower limit to the reaction probability and its potential role in tropospheric and stratospheric chemistry, Geophys. Res. Lett., 18, 17-20, 1991.

Mankin, W. G. and M. T. Coffey, Increased stratospheric hydrogen chloride in the El Chichon cloud, Science, 226, 170-172, 1984.

Mankin, W.G., and M.T. Coffey, The impact of El Chichon on the chemistry of the stratosphere, paper presented at the Norman D. Watkins Symposium on the Environmental Impact of volcanism, Graduate School of Oceanography, Narragansett, RI, March, 1986.

McElroy, M. B., R. J. Salawitch, S. C. Wofsy, and J. A. Logan, Antarctic ozone: Reduction due to synergistic interactions of chlorine and bromine, Nature, 321, 759762, 1986.

McFarland, M., B. A. Ridley, M. H. Proffitt, D. L. Albritton, T. L. Thompson, W. J. Harrop, R. H. Winkler, and A. L. Schmeltekopf, Simultaneous in situ measurements of $\mathrm{NO}_{2}, \mathrm{NO}$, and $\mathrm{O}_{3}$ between 20 and $31 \mathrm{~km}, J$. Geophys. Res., 91, 5421-5437, 1986.

Michelangeli, D. V., M. Allen, and Y. L. Yung, El Chichon. volcanic aerosols: Impact of radiative, thermal and chemical perturbations, J. Geophys. Res., 94, 18,429 $18,443,1989$.

Michelangeli, D. V., M. Allen, Y. L. Yung, R. L. Shia, and D. Crisp, Enhancement of the atmospheric radiation by an aerosol layer. Submitted to J. Geophys. Res., 1990.

Molina, M. J., T. L. Tso, L. T. Molina, and F. C. Y. Wang, Antarctic stratospheric chemistry of chlorine nitrate, hydrogen chloride and ice: Release of active chlorine, Science, 238, 1253-1257, 1987.

Pinto, J. P., R. P. Turco, and O. B. Toon, Self-limiting physical and chemical effects in volcanic eruption clouds, J. Geophys. Res., 94, 11,165-11,174, 1989.

Pollack, J. B., O. B. Toon, E. F. Danielson, D. J. Hofmann, and J. M. Rosen, The El Chichon volcanic cloud: An introduction, Geophys. Res. Lett., 10, 989-992, 1983.

Roscoe, H. K., B. J. Kerridge, L. J. Gray, R. J. Wells, and J. A. Pyle, Simultaneous measurements of stratospheric $\mathrm{NO}$ and $\mathrm{NO}_{2}$ and their comparison with model predictions, J. Geophys. Res., 91, 5405-5419, 1986.

Rossi, M. J., R. Malhotra, and D. M. Golden, Heterogeneous chemical reaction of chlorine nitrate and water on sulfuric-acid surfaces at room temperature, Geophys. Res. Lett., 14, 127-130, 1987.

Solomon, S., R. R. Garcia, F. S. Rowland, and D. J. Wuebbles, On the depletion of Antarctic ozone, Nature, 321, 755-758, 1986.

Spinhirne, J. D. and M. D. King, Latitude variation of spectral optical thickness and columnar size distribution of the $\mathrm{El}$ Chichon stratospheric aerosol layer, $J$. Geophys. Res., 90, 10,607-10,619, 1985.

Thomas, G. E., B. M. Jakosky, R. A. West, and R. W. Sanders, Satellite limb--scanning thermal infrared observations of the El Chichon stratospheric aerosol: First results, Geophys. Res. Lett., 10, 997-1000, 1983.

Tolbert, M. A., M. J. Rossi, and D. M. Golden, Heterogeneous interactions of chlorine nitrate, hydrogen chloride, and nitric acid with sulfuric acid surfaces at stratospheric temperatures, Geophys. Res. Lett., 15, 847-850, 1988.

Woods, D. C., R. L. Chuan, and W. I. Rose, Halite particles injected into the stratosphere by the $1982 \mathrm{El} \mathrm{Ch}$ chon eruption, Science, 230, 170-172, 1985.

Worsnop, D., M. Zahniser, C. Kolb, L. Watson, J. Van Doren, J. Jayne, and P. Davidovits, Mass accommodation coefficient measurements for $\mathrm{HNO}_{3}$, $\mathrm{HCl}$, and $\mathrm{N}_{2} \mathrm{O}_{5}$ on water/ice and aqueous sulfuric acid droplet surfaces, Abstracts of the Polar Ozone Workshop, Snowmass, Colorado, 9-13 May 1988.

Diane V. Michelangeli, Space Science Division, NASA Ames Research Center, Moffett Field, California 94035 Yuk L. Yung, Division of Geological and Planetary Sciences, California Institute of Technology, Pasadena, Cajifornia 91125.

Mark Allen, Earth and Space Sciences Division, Jet Propulsion Laboratory, California Institute of Technotogy, 4800 Oak Grove Drive, Pasadena, California 91109

(Received: August 24, 1990; revised: November 28, 1990; accepted: February 12, 1991.) 